\title{
Novas Perspectivas Na Investigação da Criminalidade de Massa e sua Importância para o Enfrentamento do Crime Organizado
}

Breno Freire Diniz

Polícia Federal - Brasil

天慗方

RESUMO

Este artigo tem por objeto a reflexão acerca da investigação de crimes que constituem a criminalidade de massa a partir dos resultados obtidos na execução do Portfólio Hermes da DPAT - Divisão de Repressão a Crimes Contra o Patrimônio e ao Tráfico de Armas da Polícia Federal, que teve por objetivo aumentar a eficiência no enfrentamento dos crimes de roubos e furtos contra os carteiros da Empresa de Correios e Telégrafos, na região Metropolitana de São Paulo. Os resultados obtidos nesta experiência demonstram uma inadequação do modelo de persecução criminal estabelecido no Brasil para a investigação da criminalidade de massa, por desconsiderar soluções já cientificamente embasadas que apontam para a inteligência e análise criminal como ferramentas essenciais à resposta da polícia judiciária. Ademais, o recrudescimento do combate ao fenômeno da criminalidade de massa exsurge mais relevante diante das evidências que corroboram a construção teórica da estreita relação entre a criminalidade de massa e a criminalidade organizada. Assim, parece necessária a construção de um novo paradigma para a investigação criminal que reconfigure o modelo de persecução da criminalidade de massa, adequando-o às mudanças de valores jurídicos, dogmáticos e ideológicos que estão remodelando o tradicional sistema de política criminal liberal-iluminístico, por influência, principalmente, dos nefastos reflexos da criminalidade organizada na sociedade contemporânea.

Palavra S-Chave: Investigação Criminal. Criminalidade de Massa. Criminalidade Organizada.

1 Portfólio Hermes é o conjunto de projetos executados pela DPAT para o aprimoramento das investigações criminais de crimes de roubos e furtos em detrimento da operação de distribuição dos Correios na Grande São Paulo, no período de 2012 a 2015. 
Novas perspectivas na investigação da criminalidade de massa e sua importância...

\section{INTRODUÇÃ̃o}

A forma de organização do corpo social no enfrentamento ao fenômeno criminal é o entendimento aceito para este estudo como conceito de política criminal. Neste sentido, a política criminal teria como objetivo garantir a coesão e sobrevivência do corpo social, atendendo à necessidade natural de segurança pessoal e patrimonial dos integrantes do grupo social (DELMAS-MARTY, 1986. p.42).

É natural que as políticas criminais sejam influenciadas sobremaneira pelas ideologias socioeconômicas vigentes. $\mathrm{O}$ advento dos estados nacionais modernos, resultante da simbiose entre o liberalismo econômico e a revolução tecnológica, propugnou o alicerce da corrente de política criminal liberal, a qual tem por princípio o valor liberdade como “...estado primitivo do homem, origem primeira, princípio que o Estado e a sociedade não podem nem reprimir, nem limitar..." (DELMAS-MARTY, 1986, p.45). Trata-se, obviamente, de uma corrente que tem por fundamentos o individualismo e contratualismo como razões fundamentadoras do direito de punir do estado, os quais são a viga mestra de uma política criminal pautada pela limitação ao poder estatal face os direitos individuais. É o que diz a lição de Cesare Beccaria (2003, p.19), expoente importante desse sistema de política criminal:

[...] somente a necessidade obriga os homens a ceder uma parcela de sua liberdade; disso advém que cada qual apenas concorda em pôr no depósito comum a menor proporção possivel dela, quer dizer, exatamente o necessário para empenhar os outros em mantê-lo na posse do restante.

A reuniäo de todas essas pequenas parcelas de liberdade constitui o fundamento do direito de punir. Todo exercício do poder que desse fundamento se afaste constitui abuso e não justiça; é um poder de fato e não de direito, constitui usurpação e jamais um poder legitimo.

Tal concepção foi amplamente desenvolvida na construção dos estados democráticos de direito, os quais ergueram suas estruturas constitucionais com foco na proteção do indivíduo face o poder coercitivo do estado, em um ciclo que desencadeou o que é reconhecido atualmente, por alguns autores, como o "hipergarantismo". No entender de Canotilho: 
No plano do direito penal (e processual penal) as refracçóes do hipergarantismo explicam também a superlativização da cultura iluminístico-liberal centrada na proteção do criminoso com quase completo desprezo da vitima. (CANOTILHO, 2009, p.20)

O que há de se ressaltar é que toda essa construção teórica se deu sob o paradigma de uma criminalidade clássica, a qual pode ser encontrada na própria obra de Beccaria, que descreve, dentre outros, o crime de homicídio, o roubo, os crimes contra a honra e contra a liberdade, o contrabando, e também o adultério, a pederastia, o infanticídio, etc. Enfim, categorias de crimes que compõem ou já integraram a maioria dos ordenamentos jurídicos ocidentais. (BECCARIA, 2003).

Neste sentido, a criminalidade de massa parece ser facilmente identificável dentre os crimes definidos há muito na construção do direito penal moderno, visto que se trata de um fenômeno criminal caracterizado pela lesão a bens jurídicos bem definidos, como a vida, a integridade física das pessoas e o patrimônio. Ademais, não há restrições significativas para a identificação da autoria delitiva. O conceito de criminalidade de massa, entretanto, não obstante pareça facilmente apreensível, ainda possui especificidades que precisam ser trabalhadas pelos doutrinadores que o utilizam. No entendimento de Guinote, por exemplo, “...inclui todos os tipos de crimes que são cometidos frequentemente e em que as vítimas são facilmente identificáveis". (GUINOTE, 2009, p. 126).

$\mathrm{O}$ autor citado complementa ainda que a criminalidade de massa majoritariamente abrange a pequena criminalidade, que compreenderia o furto, roubo, dano, agressão, injúria, etc., crimes que apresentam elevados índices criminais. Ademais, ao contrário da criminalidade organizada, na criminalidade de massa a vítima seria facilmente identificável, sendo que o crime afetaria muito mais o indivíduo, "[...] exponenciando majoritariamente o índice de insegurança subjetiva”. (GUINOTE, 2009, p. 127). Ousaríamos acrescentar que uma das características fundamentais desse tipo de criminalidade, parece ser a fácil constatação também da autoria, não se tratando de um fenômeno criminal de autoria e modo de ação sub-reptício.

É notória a distinção elaborada por Hassemer entre criminalidade de massa e criminalidade organizada, segundo o qual elas seriam radicalmente distintas no tocante à origem, potencial de ameaça e possibilidade de combate (HASSEMER, 1993). Entretanto, novos estudos apontam 
Novas perspectivas na investigação da criminalidade de massa e sua importância...

para a possível existência de interferências e ingerências mútuas entre essas supostas diferentes realidades criminais.

A apreensão dos conceitos de criminalidade comum e a criminalidade organizada, no entanto, enseja dificuldades significativas, com reflexos na problemática da construção de uma tipificação penal adequada à realidade do crime organizado. No entender de Eliomar da Silva Pereira:

A questão é que o crime organizado não existe como realidade jurídica; o que existe é uma criminalidade difusa, fruto mais de uma desorganização social e estatal, de forma que pode interferir no Estado ou até mesmo suplantá-lo. Há, portanto, no máximo, uma criminalidade organizada, ou mais precisamente a organizar-se: crimes que se praticam de forma organizada. (PEREIRA, 2015, p. 16-17).

O mesmo autor observa que a nova Lei 12.850/12 também não enfrentou o problema conceitual, assim como a Lei 9.034/95, visto que preferiu criminalizar o sujeito do crime a enfrentar a definição do crime objetivamente considerado. (PEREIRA, 2015). Portanto, ele difere do entendimento de HASSEMER, ao estabelecer, em concordância com o professor MANOEL VALENTE, que "[... ]o crime organizado sobrevive se o crime de massa estiver bem enraizado e bem embrenhado na sociedade". (VALENTE, 2009 apud PEREIRA, 2015, p. 17). Por fim, o professor Eliomar justifica assim a inexistência de um tipo penal sobre crime organizado e a preferência por tipificar a organização criminosa:

Ignora-se o crime organizado como tipo penal, pois este se extrai da tipologia geral do Direito Penal. Não há novos crimes, mas os mesmos crimes que se praticam em uma dimensão espácio-temporal diferente e que nos transmitem a sensação de que algo diverso está a acontecer. $E$ de fato parece estar. Em comum, todas essas expressões têm a ideia de organização. (PEREIRA, 2015, p. 17-18).

Portanto, não só a criminalidade de massa, mas também a criminalidade organizada, possuem por substrato a prática de crimes comuns, entendidos como os delitos clássicos da definição do direito penal, apesar de ser evidente que o alcance da criminalidade organizada é bem maior para a prática de outros delitos econômicos, financeiros e relacionados com o poder político, os quais se identificam com a proposta conceitual de Sutherland (2004), como crimes de "colarinho branco". 
A dificuldade em delimitar com precisão o fenômeno da criminalidade organizada ganha importância na medida em que cresce a preocupação sobre uma resposta efetiva da persecução criminal a essa ameaça, em especial ao sistema de política criminal "liberal-iluminístico" ou "direito penal do cidadão", o qual, para Canotilho:

$$
\begin{aligned}
& \text {...estrutura-se segundo um código de princípios de direto penal e de } \\
& \text { direito processual penal que agora encontram dignidade constitucio- } \\
& \text { nal formal na maioria das leis fundamentais (principio da legali- } \\
& \text { dade, principio da não retroatividade das leis penais, princípio do } \\
& \text { non bis in idem, princípio da inocência do arguido, princípio das } \\
& \text { garantias de defesa do réu, princípio do acusatório, principio da re- } \\
& \text { serva do juiz, etc.) (CANOTILHO, 2009, p.22) }
\end{aligned}
$$

O direito penal contra o inimigo seria uma nova forma de enfrentar o crime, embasado por valores jurídicos, dogmáticos e ideológicos com profunda influência sobre o sistema penal americano e europeu. Suas propostas constitucionais e penais destinam-se a informar as políticas e legislações criminais anti-terroristas, ademais da criminalidade organizada e da delinquência sexual (pedofilia e pornografia on line). (CANOTILHO, 2009).

A questão que se apresenta é como se delineará o enfrentamento da criminalidade de massa diante da dupla orientação de política criminal, a primeira pautada no garantismo, orientador do direito penal do cidadão, e a outra no direito penal do inimigo, que visa o enfrentamento de uma realidade criminal que exige um "direito penal de emergência", em detrimento de um "direito penal de permanência”, na nomenclatura dada por Canotilho (2009).

O problema se agrava quando admitimos a já mencionada relação entre a criminalidade de massa e a criminalidade organizada. Em recente artigo sobre o tráfico de seres humanos diante da lei espanhola, a professora Nieves Sanz Mulas nos dá um exemplo dessa relação. Segundo ela, a complexidade do fenômeno migratório mundial obriga que o tráfico de seres humanos seja assumido por redes criminais integradas por pessoas que se dividem nos papéis de recrutamento, fornecimento de documentos falsos, agentes de viagem ou transportadores, e, já no país de destino, proporcionem a exploração do trabalho ou de atividades ilícitas com a mão de obra dos imigrantes. É evidente, no entender da professora, que a atratividade econômica deste tipo de crime organizado transnacional dá-se com a exploração laboral e sexual do imigrante, bem como pela rentabilidade derivada da participação destes em atividades delitivas, como o transporte de droga, o furto ou até mesmo a prática da mendicância. (MULAS, 2009). 
Novas perspectivas na investigação da criminalidade de massa e sua importância...

A realidade do tráfico de drogas, no entanto, nos dá um exemplo ainda mais evidente das conexões e interpenetrações entre a criminalidade de massa e a criminalidade organizada. No Brasil, uma análise detida sobre a realidade criminal em favelas e bairros pobres demonstra que poderiam ser traçados uma série de eixos lógicos comuns para a compreensão da estruturação das atividades criminosas. Em uma primeira fase, em locais caracterizados por problemas de vulnerabilidade social, rapidamente há um gradativo crescimento da violência ligada a assaltos e venda de drogas. Em seguida, constata-se uma fase de depuração dos pequenos grupos criminosos, com ciclos de violência para se sobreporem (nesta fase, é natural que grupos locais passem a filiar-se a facções criminosas para o recrudescimento do crime e do avanço territorial). Já em uma terceira fase da estruturação criminosa, após configurada a supremacia de um grupo em determinada faixa territorial, sendo ligado à uma facção criminosa, sobrepõe-se uma visão de mercado, em detrimento das relações meramente societárias. Além de uma minimização dos conflitos, busca-se uma ampliação das atividades criminosas e comerciais, as quais não se limitam ao tráfico de drogas, roubos e furtos, mas ampliam-se a atividades ilegais tais como a venda informal de serviços e bens públicos, como a distribuição de gás, controle do transporte e segurança e TV por assinatura. Além disso, configura-se uma rede de proteção policial e conexôes políticas, com a eleição de representantes ligados ao interesse da organização criminosa. (BEATO; ZILLI, 2012)

Portanto, a diferenciação dos diversos estágios da estruturação das atividades criminosas "...adquire grande importância para a produção de políticas públicas, uma vez que a identificação clara dessas etapas acarreta formas distintas de controle e enfrentamento" (BEATO; ZILLI, 2012, p. 95).

O estudo complementa que:

(...) a lógica societária que prevalece nos primeiros momentos exige açóes distintas daquelas exigidas para o enfrentamento de uma lógica de guerra envolvendo altos graus de corrup̧ãa e cooptação policial, existentes em estágio marcado pela competição entre grupos e extinção de alguns deles. Da mesma maneira, quando se inicia de fato uma atividade de crime organizado, seu controle exigirá o envolvimento de estratégias e atores bastante articulados, uma vez que o problema passa a envolver, inclusive, atores e setores governamentais. (BEATO; ZILLI, 2012, p. 95). 
De qualquer forma, dois pontos de partida podem ser utilizados para o presente trabalho: a importância da efetividade no enfrentamento à criminalidade de massa, não só pelos efeitos benéficos na sensação de segurança no meio social, mas pela conexão existente entre essa criminalidade de massa e o crime organizado, bem como pela busca por uma alternativa de política criminal adequada ao fenômeno da criminalidade de massa, em um ponto de equilíbrio entre o direito penal do inimigo e o garantismo penal, sem se perder de vista a necessidade de incremento do enfrentamento desse fenômeno.

Com efeito, nota-se uma preocupação diminuta na construção de políticas criminais ou ferramentas processuais eficazes ao enfrentamento da criminalidade de massa, com séria repercussão à eficácia da investigação criminal. A seguir, faremos algumas reflexões sobre os resultados encontrados na implantação do Portfólio Hermes por parte da DPAT - Divisão de Repressão a Crimes Contra o Patrimônio e ao Tráfico de Armas, o qual teve por objeto a diminuição do número de ocorrências dos roubos e furtos em detrimento da distribuição de mercadorias e correspondências dos Correios na Região Metropolitana de São Paulo nos anos de 2012 a 2015, à luz das considerações teóricas já expostas sobre a conexão entre a criminalidade de massa e o crime organizado, e da adequação de uma política criminal que tenha reflexos efetivos na dissuasão desse tipo de criminalidade de massa, sem que se perca de vista os princípios informadores do direito penal do cidadão.

\section{A Experiência da Polícia Federal no Enfrentamento da Criminalidade de Massa}

O Departamento de Polícia Federal tem como atribuição a apuração, dentre outros delitos, dos crimes em detrimento das Empresas Públicas Federais, conforme expressamente previsto no Art. 144, $\$ 1^{\circ}$, I da Constituição Federal. Por conseguinte, o mandamento constitucional atrai toda sorte de infrações penais contra a Empresa Pública de Correios e Telégrafos do Brasil - CORREIOS - responsável pelo monopólio da entrega de cartas, telegramas e correspondências agrupadas em todo o território nacional.

Dentro do Departamento de Polícia Federal, a área pertinente aos crimes de furto e roubo contra os Correios é de responsabilidade da Divisão de Repressão a Crimes Contra o Patrimônio e ao Tráfico de Armas - DPAT, 
Novas perspectivas na investigação da criminalidade de massa e sua importância...

sendo que nas Superintendências Regionais, tais crimes estão afetos às Delegacias Especializadas de Crimes Contra o Patrimônio - DELEPAT.

Ocorre que, os furtos e roubos contra a área de distribuição dos Correios, em especial, na região Metropolitana de São Paulo, se apresenta como um grande desafio à Polícia Federal, já que a realidade criminal enfrentada é tipicamente da criminalidade de massa, ou nos dizeres dos estudiosos ingleses, high-volume crime.

Os números consolidados de ocorrências de roubos e furtos a carteiros na operação de distribuição dos Correios são extremamente significativos a partir da presente década. Nota-se um crescimento vertiginoso, impulsionado pelo aumento do comércio eletrônico, o qual utiliza os serviços dos Correios para a entrega das mercadorias comercializadas. Somente o estado de São Paulo responde por aproximadamente 60\% das ocorrências do país, e em sua grande maioria na região metropolitana.

A primeira constatação verificada pelo estudo da DPAT é que, não obstante a atribuição da Polícia Federal para a investigação de tais crimes, na regiấo metropolitana de São Paulo, as ocorrências delituosas são registradas nas Delegacias de Polícia Civil. Este procedimento é resultado de acordo firmado entre a Empresa Pública e a Secretaria de Segurança Pública de São Paulo. Assim, os carteiros roubados e furtados são orientados a comparecerem nas delegacias mais próximas aos eventos delituosos para o registro do Boletim de Ocorrência.

O problema é que as comunicações dos crimes somente chegam à Polícia Federal por meio de ofícios das delegacias de polícia civil encaminhando os Boletins de Ocorrências registrados. Tal procedimento provoca distorções, visto que o conhecimento do fato criminoso é dado à Polícia Federal - a qual possui atribuição para investigar - apenas em momento muito posterior à ocorrência delituosa. São dias, ou mesmo semanas após o crime, o momento em que a notitia criminis é entregue à Polícia Federal.

Um aspecto importante é que a maioria das ocorrências registradas não são encaminhadas pela Polícia Civil à Polícia Federal, o que significa que apenas parte das ocorrências delituosas contra os carteiros chegam ao conhecimento oficial da Polícia Federal. Tal situação foi constatada no levantamento realizado em 2011, o qual tomou por base os dados comparativos entre o 
número de ocorrências registradas no SEPAT $/ \mathrm{SIRI}^{2}$ e o número de Inquéritos Instaurados pelo Núcleo da Polícia Federal nos Correios.

Outro fator verificado, ainda mais relevante, demonstra que as ocorrências delituosas comunicadas à Polícia Federal, consistentes basicamente no Boletim de Ocorrência registrado na Polícia Civil, seguem o trâmite usual de qualquer notitia criminis. Assim, com fundamento em preceitos estabelecidos indistintamente para qualquer comunicação de crime, são tratadas individualmente com despacho para instauração de inquérito policial, já que versam sobre fatos típicos. O resultado é que, apenas em 2011, foram instaurados 974 inquéritos policiais pela DELEPAT/SP, a maioria absoluta para a investigação das ocorrências contra a operação de distribuição dos Correios. No mesmo ano, foram relatados 603 inquéritos.

Entretanto, segundo aponta Silva Júnior (2014, p. 62), o qual confeccionou brilhante monografia abordando a experiência do Portfólio Hermes:

O Núcleo contava historicamente com elevado indice estatístico no item IPLs Relatados, porém preocupava quanto ao quesito Número de Indiciados. A baixa quantidade de indiciamentos em comparação ao número relatado refletia a necessidade de ações inovadoras que auxiliassem na identificação de autoria, bem como incentivassem o reconhecimento, por parte dos carteiros.

É perceptível que a persecução criminal individualizada, sem o cotejo de informações do todo das ocorrências, quando se trata de criminalidade de massa, se revela menos produtiva. Além disso, o esforço investigativo uniformizado, sem a seleção das ocorrências com maior viabilidade de solução, é fator que vai de encontro à eficácia das investigações.

Por fim, os inquéritos policiais são instaurados até semanas após a data da ocorrência delituosa, haja vista o tempo necessário para que os Boletins de Ocorrências sejam remetidos pela Polícia Civil à Polícia Federal e para que sejam vencidos os trâmites burocráticos de praxe. $\mathrm{O}$ fato é que, na maioria absoluta dos casos, o carteiro vítima é ouvido até meses após a ocorrência pela autoridade policial, conduta diametralmente oposta ao proposto nos estudos ingleses.

2 SEPAT e SIRI são sistemas internos dos Correios que servem ao registro das ocorrências delituosas. 
Novas perspectivas na investigação da criminalidade de massa e sua importância...

\section{Novas Perspectivas para a Investigação Criminal dos Crimes Contra os Correios}

Neste momento, cabe refletir sobre a necessidade de novas perspectivas para a persecução criminal na criminalidade de massa. A nossa legislação processual é construída sob um modelo ortodoxo de processo penal, centrado na obrigatoriedade e indisponibilidade da ação penal e da própria atuação da persecução penal pré-processual. Tal posicionamento pode ser exemplificado pelos ensinamentos de Tourinho Filho (1994, p.177), que diz:

Os órgãos incumbidos da persecução não podem possuir poderes discricionários para apreciar a conveniência ou oportunidade da instauração do processo ou do inquérito.

Precisamos indagar se tal posicionamento é adequado ao fenômeno da criminalidade de massa e se permite uma resposta eficaz dos órgãos de persecução penal. Em verdade, há poucos estudos acerca da atuação da polícia judiciária no Brasil e também parcos trabalhos científicos formulados a partir da própria experiência das polícias judiciárias. Trata-se de situação similar ao que ocorria na Inglaterra, até o início da década de 1970. Segundo a pesquisadora inglesa Krista Jansson (2005), do Crime Reduction and Community Safety Group, até o início da década de 70, as investigações policiais atraíram pouco interesse das pesquisas, pelo que não havia estudos analíticos da função investigativa. Porém, a partir desta época, o trabalho da polícia passou a ser objeto de diversos estudos e pesquisas empíricas tanto nos Estados Unidos, quanto na Grã-Bretanha.

Nos Estados Unidos, os focos das pesquisas foram influenciados por dois importantes estudos ${ }^{3}$ que examinaram como os crimes eram solucionados e a contribuição que a polícia tinha para o processo de detenção. Ambos os estudos observaram que muito tempo do trabalho policial era desperdiçado em investigações de crimes que eram impossíveis de serem solucionados. Também enfatizaram a importância do primeiro atendimento à ocorrência na obtenção de informações sobre os suspeitos fornecidos pelas vítimas (ISAACS; GREEWOOD apud JANSSON, 2005).

3 Tratam-se dos estudos de Isaacs e Greewood, conf. (Isaacs, H. (1967) A Study of Communications, Crimes and Arrests in a Metropolitan Police Department. Task Force Report: Science and technology. Washington, DC: UN Government Printing Office) e (Greenwood, P. (1970) An Analysis of the Apprehension Activities of the New York City Police Department. New York, NY: Rand). 
A partir desses estudos iniciais, $\mathrm{Eck}^{4}$ (apud JANSSON, 2005) formulou então uma nova teoria de como os casos criminais são resolvidos a partir de duas hipóteses antagônicas. A primeira, defendendo que a solução dos crimes são consequência do acaso de algumas circunstâncias, e a segunda, defendendo que, independentemente dos obstáculos ocasionados por fatores como ausência de testemunha ou pistas, os esforços investigativos é que são determinantes para a solução ou não dos casos criminais. Eck chamou essas hipóteses, respectivamente de "resultado das circunstâncias" e "resultado dos esforços", e criou uma nova hipótese, denominada, hipótese da triagem, dividindo os casos em três grupos:

- a) "Self-solvers" - Há claras evidências e informações sobre o crime, não requerendo muito trabalho investigativo (ex. casos em que o suspeito é preso em flagrante);

- b) Casos que podem ser solucionados pois há pistas e informações disponíveis, mas é preciso trabalho investigativo para obter tais informações;

- c) Casos que não podem ser solucionados mesmo com quantidade razoável de trabalho investigativo, ou podem ser, em verdade, insolúveis.

Segundo Eck (apud JANSSON, 2005), o foco da investigação criminal está no grupo "b", no qual as ações de investigação se mostram importantes e úteis para a elucidação dos casos. Ele formulou sua híbrida hipótese com base na análise de 320 roubos e 3360 furtos. Os resultados indicaram que as informações disponíveis após as investigações iniciais estão significantemente relacionadas com a probabilidade de fazer uma prisão durante o desenvolvimento das investigações e concluiu ainda que a investigação preliminar e as secundárias foram cruciais para a solução dos crimes, mas são as informações obtidas na investigação preliminar que guiam o desenrolar das investigações e fornecem os vínculos necessários à elucidação dos crimes.

Os estudos científicos acerca da investigação criminal não ficaram adstritos à academia. A ACPO - Association of Chief Police Officers, do Reino Unido, publicou, em 2002, o "Investigation of Volume Crime

4 Eck, J.E. (1979) Managing Case Assignments: the burglary investigation decision model replication. Washington, DC: Police Executive Research Forum.

Eck, J.E. (1983) Solving Crimes: The Investigation of Burglary and Robbery. Washington, DC: Police Executive Research Forum.

Eck, J.E. (1984) Interim consultant report on burglary case screening. Metropolitan Police Management Services Department. (Unpublished) 
Novas perspectivas na investigação da criminalidade de massa e sua importância...

Manual", o qual incorpora diversos dos conhecimentos obtidos nas pesquisas realizadas. A ACPO (2002) formulou um roteiro das investigações em "high volume crime", o qual funda-se no entendimento de que a investigação criminal é um dos fatores preponderantes para o sucesso de elucidação dos casos, além da contribuição da vítima e da população. Ademais, o manual distingue os dois tipos principais de abordagem do crime: o reativo e o proativo. Nas investigações reativas, a polícia responde às ocorrências que chegam ao seu conhecimento. Já as investigações proativas são iniciadas pela polícia, frequentemente baseadas em informações de inteligência, com foco no ofensor muito mais que na ofensa. O mais importante é que esses dois tipos de investigação não são excludentes, pelo contrário, estão extremamente interligados.

O manual de Investigações de High Volume Crimes (ACPO, 2002) e os estudos analisados por JANSSON (2005), permitem a visualização de um roteiro investigativo para a criminalidade de massa nos seguintes parâmetros:

- 1) comunicação e resposta inicial - visa obter e registrar as informações sobre a ocorrência, orientar a vítima, classificar o grau da ofensa e alocar as forças policiais para atendimento;

- 2) avaliação da cena - objetiva tentar identificar o que aconteceu de fato, tentar identificar o autor do delito e avaliar se é possível sua imediata prisão, e, caso não seja possível a prisão, avaliar as informações possíveis que possam viabilizar a imputação da autoria;

- 3) Coleta de evidências - Trata-se da investigação preliminar, e inclui a tomada dos depoimentos da vítima e das testemunhas, a coleta das imagens de CFTV que possivelmente tenham registrado o fato, o cumprimento dos procedimentos, a utilização dos sistemas disponíveis, o registro das ações realizadas e a circulação da informação.

- 4) Triagem dos casos e atribuição para investigação posterior ou adicional - trata-se de decisão sobre os casos que serão ou não submetidos a investigação adicional posterior, baseada na probabilidade de solução do caso dada a coleta de evidências até o momento obtidas. SCREENING $M O D E L$

- 5) Investigação secundária - continuação das investigações após a triagem dos casos considerados com probabilidade de serem solucionados. 
Segundo JANSSON (2005), as investigações secundárias devem ser efetivadas apenas após o processo de triagem das ocorrências ${ }^{5}$, seja ele formal ou informal, principalmente quando se trata de "volume crime offenses". A qualidade da informação obtida na investigação preliminar é preponderante para a eficiência da triagem dos casos para a investigação secundária. Além disso, há que se considerar que os modelos de triagem utilizados têm por fundamento natural bloquear a continuidade dos trabalhos investigativos $\mathrm{da}$ vasta maioria dos casos, submetendo à segunda fase da investigação apenas as ocorrências solucionáveis. E finaliza:

Volume crime investigations are complex and often do not advance in a linear fashion, therefore a degree of flexibility is needed in how best to progress the investigation. (JANSSON, 2005, p. 54).

Conforme visto, os achados relatados na persecução criminal procedida pela Polícia Federal sobre os crimes de roubos e furtos em detrimento da distribuição de correspondências e encomendas pelos Correios, não obstante obedeçam a lógica do nosso sistema processual penal, em verdade são dissonantes com as conclusões científicas acima esposadas na área do enfrentamento da criminalidade de massa, em especial nos Estados Unidos e na Inglaterra, as quais foram incorporadas à investigação de "high volume crime" pela polícia inglesa.

\section{O Portfólio Hermes}

Conforme já mencionado, os crimes contra os Correios são comunicados à Polícia Civil de São Paulo, a qual não possui atribuição para a apuração. O registro da ocorrência é feito burocraticamente, sem a atenção devida às fases de 1 a 3 do roteiro estabelecido no modelo inglês, que prevê a importância da comunicação e resposta inicial, avaliação da cena e coleta de evidências.

Note-se ainda que apenas parte das ocorrências chegam ao conhecimento oficial da Polícia Federal, dias ou semanas depois, por meio do encaminhamento do B.O registrado na Polícia Civil para a Superintendência da

5 A autora relata diversos modelos de triagens das ocorrências. Alguns deles, não permitem uma interpretação livre dos investigadores, e são baseados nas estatísticas das investigações anteriores. É o caso do modelo construído nos Estados Unidos pela Stanford Research Institute (SRI). O citado modelo dava um determinado peso para cada dado obtido na investigação preliminar e ao final atribuía uma nota ao caso, a qual teria que ter um valor mínimo determinado para que o crime fosse considerado solucionável e reputada viável a continuidade da investigação. 
Novas perspectivas na investigação da criminalidade de massa e sua importância...

Polícia Federal, em São Paulo. Portanto, a maioria das ocorrências passam a compor uma cifra negra para a Polícia Federal, a qual tem atribuição para investigar os delitos de roubos e furtos contra os carteiros.

Constata-se também que não há triagem/análise dos casos por parte da Polícia Federal, etapa primordial no modelo proposto no estudo inglês. A análise feita pela Corregedoria segue o roteiro baseado num modelo processual penal frontalmente dissonante do mencionado, o qual sustenta a obrigatoriedade padrão de instauração da investigação criminal por parte da polícia judiciária desde que presente a justa causa para a investigação, a qual funda-se exclusivamente na materialidade delitiva, isto é, se os fatos investigados configuram fato típico, em tese. Sobre o tema, a doutrina ressalta que somente cabe o indeferimento da instauração do inquérito policial por parte da autoridade policial "...sob o fundamento de atipicidade do fato, isto é, de não encontrar, o fato narrado, correspondência com nenhum tipo penal”. (PACELLI; FISCHER, 2012, p. 25).

Assim, no modelo verificado em São Paulo, não importa o quantitativo de ocorrências, tampouco as peculiaridades de cada uma e os diferentes graus de solubilidade de cada ocorrência investigada. Todos os fatos são considerados uniformemente, mesmo que tal procedimento implique, na prática, em instauração de milhares de inquéritos policiais, sob a responsabilidade de um efetivo diminuto, sem a mínima chance de proporcionar uma resposta efetiva a tais investigações.

A necessidade de instauração obrigatória de inquéritos policiais, os quais são comparáveis às "investigações secundárias" do modelo inglês, provoca outra consequência nefasta constatada durante os estudos do Portfólio Hermes. As vítimas dos roubos e furtos aos Correios são os carteiros e funcionários terceirizados dos Correios. Estes, diante do trâmite já mencionado e do grande número de inquéritos, são ouvidos efetivamente pela autoridade policial até meses após o fato delituoso, com graves prejuízos à coleta de evidências, que, no modelo inglês, conforme visto, ocorreria logo após a comunicação do fato delituoso à polícia, isto é, em fase de investigação preliminar.

Por óbvio, principalmente no crime de roubo, a vítima tem um papel preponderante na solução do crime. Em estudo sobre os fatores que levam à solução do crime (SKOGAN; ANTUNES, 1979, apud JANSSON, 2005), é ressaltado que as investigações que resultaram na identificação e prisão dos 
autores devem-se em sua quase totalidade à contribuição da vítima e das testemunhas. Portanto, relegar a contribuição da vítima à fase posterior a formalização da investigação, com a sua oitiva meses após o fato, representa uma prática que contribui para a ineficiência da investigação.

O Portfólio Hermes, conforme mencionado, é composto de vários projetos inter-relacionados, com objetivo de repressão à criminalidade que atinge a operação de distribuição de correspondências e mercadorias dos Correios na região metropolitana de São Paulo. A coluna fundamental do Portfólio Hermes é a mudança do processo para tratamento das ocorrências de roubos e furtos contra os carteiros na região metropolitana de São Paulo. Trata-se de uma remodelagem do fluxo da informação, a qual pode ser resumida no diagrama a seguir:

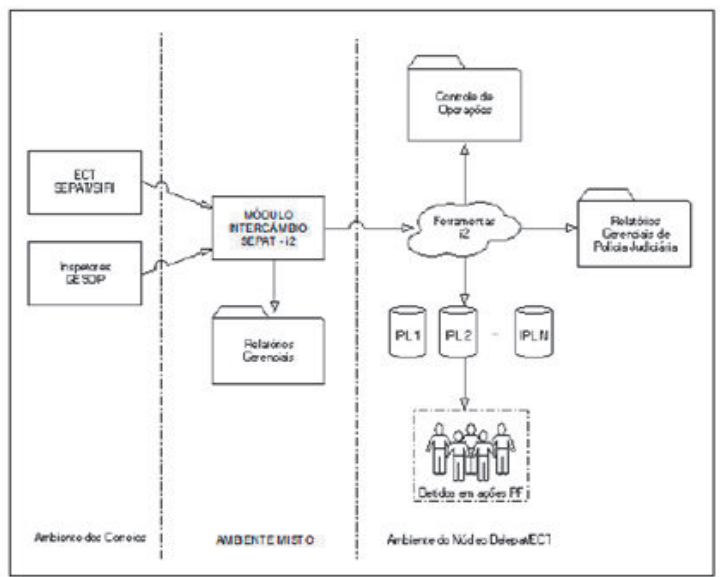

Fonte: Relatório de Especificação do Sistema Hermes. Brasilia: DPAT, fevereiro/2013.

Diagrama 1. Proposta de fluxograma da investigação (Projeto hermes):

Sem prejuízo da comunicação feita à Polícia Civil, a qual decorre de acordo firmado entre os Correios e a Secretaria de Segurança Pública do Estado de São Paulo, o novo fluxograma para o processo de tratamento das ocorrências prevê o aproveitamento das informações que alimentam o Sistema de Segurança Patrimonial (SEPAT) ${ }^{6}$ dos Correios. Nessa fase, sob a supervisão dos policiais federais lotados no Núcleo da DELEPAT, no próprio ambiente dos Correios, os

6 O SEPAT é necessariamente alimentado com diversas informações sobre o fato criminoso, mediante comunicação direta por parte do carteiro roubado ao inspetor de segurança dos Correios. 
Novas perspectivas na investigação da criminalidade de massa e sua importância...

carteiros vítimas de roubos devem ser ouvidos imediatamente após a ocorrência ou em prazo não superior a $24 \mathrm{~h}$ do fato delituoso, preenchendo os campos do sistema SEPAT e do Sistema Hermes ${ }^{7}$, os quais foram pensados para a coleta de todos os dados essenciais sobre as ocorrências delituosas. Assim, garante-se a retomada da fase preliminar de coleta de dados sobre os delitos e oferta-se amparo à vítima, ouvindo-a imediatamente após o fato. Ressalte-se que, diante da avaliação superficial dos casos (semelhante à fase de "avaliação da cena"), outras medidas de coleta de dados devem ser providenciadas, tais como a perícia papiloscópica ou de local, diligências no local do crime e a obtenção de imagens em CFTV que tenham flagrado a ação criminosa (medidas somente possíveis diante da celeridade na comunicação do delito à polícia incumbida da investigação criminal). Todos estes atos constituem uma fase preliminar da investigação.

Conforme exposto, os dados obtidos são lançados no SEPAT e no Sistema Hermes, o qual também realiza a função de "Módulo Intercambio" entre os dados lançados no SEPAT e no Sistema Hermes e o I2 do CINTEPOL da Polícia Federal. Portanto, os dados de todas as ocorrências delituosas de roubos e furtos contra os correios lançados no SEPAT e no Sistema Hermes são enviados automaticamente ao IBASE do I2 CINTEPOL, com a finalidade de serem analisados em uma fase de triagem das ocorrências.

Abaixo, vemos a tela principal do Sistema Hermes:

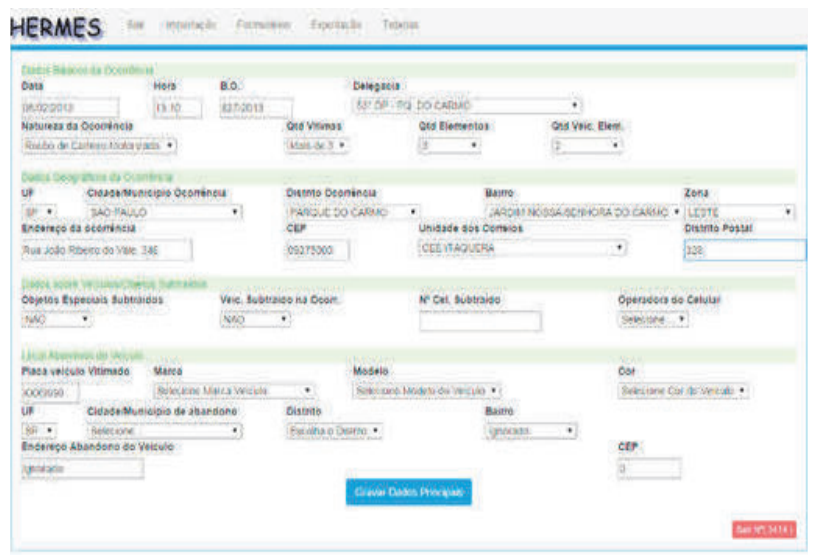

Figura 01. Tela inicial do Sistema Hermes

7 O Sistema Hermes é um software que foi construído em parceria entre a Polícia Federal e os Correios, no qual são registrados todos os dados e circunstâncias que interessam às investigações criminais contra os Correios. Estes dados, juntamente com o banco de dados do SEPAT, estão aptos a serem recepcionados automaticamente pelo IBASE do I2, para a fase de triagem das ocorrências. 
A utilização do I2 para a análise das ocorrências delituosas é uma característica marcante do Portfólio Hermes. Somente é possível essa análise em razão da forma parametrizada como são coletados os dados, os quais são “...categorizados acerca das peculiaridades físicas dos autores, das armas utilizadas no assalto, dos veículos usados na fuga e locais de abandono das viaturas da ECT subtraídas nas ações". (SILVA JÚNIOR, 2014, p. 66).

A análise/triagem das ocorrências obedece ao tirocínio e às características das ocorrências. Tomemos um exemplo primário de um roubo em que uma moto vermelha de determinada marca tenha sido abandonada na fuga pelos criminosos em razão da chegada da Polícia Militar ao local. Na nova sistemática, é possível fazer uma análise rápida e precisa de outras ocorrências, em determinado raio territorial, em que o veículo utilizado para fuga tenha sido uma moto vermelha com as mesmas características. A partir daí, podem ser cotejadas as informações para verificar se nas outras ocorrências há evidências que concluam ser o mesmo autor do delito ou que permitam o aprofundamento das investigações.

Tomemos outro exemplo, em que a Polícia Militar logre êxito em prender em flagrante o criminoso. Em uma pesquisa rápida no I2, considerando o armamento utilizado, âmbito territorial, características físicas, etc, seria possível verificar em poucos minutos outras ocorrências possivelmente praticadas pelo criminoso, possibilitando a inquirição do suspeito e a obtenção de relação das vítimas para posterior reconhecimento e imputação de autoria.

Enfim, são inúmeras as formas de análise e triagem das ocorrências para o aprofundamento das investigações. Os recursos de investigação seriam despendidos apenas quando se vislumbrasse a viabilidade de identificação da autoria, sendo o inquérito policial instaurado a partir de informação confeccionada após análise feita com o auxílio do I2. Os esforços investigativos seriam otimizados na análise de inteligência e nas investigações viáveis, em consonância, como vimos, com o que há de mais moderno em estudos no enfrentamento da criminalidade de massa.

Abaixo é possível ver o template do I2 já adaptado com os dados referentes às ocorrências delituosas contra os correios: 


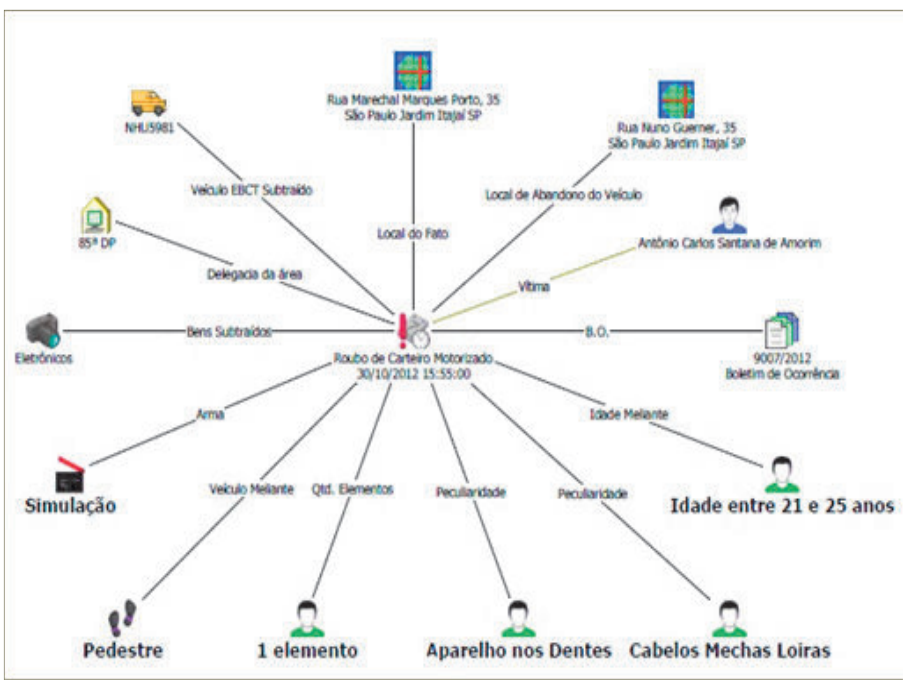

Diagrama 2. Template do I2 adaptado aos crimes contra os Correios

É importante frisar ainda que a nova sistemática do Portfólio Hermes corrige a subnotificação constatada no processo tradicional. Todas as ocorrências seriam registradas no SEPAT/Sistema Hermes, sem qualquer dependência de B.O. de outra instituição policial, e os dados já estariam à disposição da Polícia Federal, em sistema sujeito a auditoria pela Corregedoria e controle externo da atividade policial. Ademais, e o que é mais importante, uma ocorrência considerada individualmente, aparentemente sem solução em um dado momento, pode ter a autoria esclarecida quando cotejada com outros fatos delituosos analisados. Portanto, a triagem não descarta a ocorrência, esta permanece sujeita à análise na base de dados e a qualquer momento pode ser útil para a solução de determinados fatos delituosos interligados.

O novo modelo foi objeto de dois pilotos implementados na região metropolitana de São Paulo, em momentos diferentes: o primeiro, no período de 30/10/2012 a 30/11/2012) abrangendo as ocorrências do bairro Jardim Mirna, na Zona Sul de São Paulo, e o segundo, no período de 04/02/2013 a 04/03/2013, referente às ocorrências nos bairros de Santo Amaro, Vila Nova Cachoeirinha e Itaquera.

No primeiro piloto, no bairro Jardim Mirna, verificou-se uma queda de $85 \%$ no número de ocorrências. No segundo, também se constatou uma 
considerável redução no número de ocorrências, sendo no percentual de $9 \%$ em Santo Amaro, 43,4\% em Itaquera e 60,5\% em Vila Nova Cachoeirinha.

Mesmo após o período da implementação dos pilotos, a partir das informações elaboradas, foram realizadas 10 operações de inteligência integradas com ações operacionais, resultando na detenção em flagrante de 11 pessoas envolvidas nos delitos contra os correios, e na solicitação de duas prisões preventivas. (SILVA JÚNIOR, 2014).

Por fim, o Portfólio Hermes envolveu ainda ações tático operacionais, municiadas por informações de inteligência. Planejadas em julho/2012 e implementadas em agosto e setembro de 2012, tais ações contaram com o apoio de policiais do COT e da DELEPAT/SP. Foram presas em flagrante 10 pessoas, apreendida vasta quantidade de produtos roubados e identificados 02 imóveis utilizados para armazenamento de mercadorias roubadas. Como resultado, os índices de ocorrências caíram mais de 50\% em relação aos meses anteriores, em Itaquera, local escolhido para as ações.

O conjunto de medidas implementadas por ocasião dos Projetos envolvendo o Portfólio Hermes, em especial a nova estratégia de instauração e aprofundamento apenas das investigações viáveis, trouxe uma gama de informações de inteligência que servem à retroalimentação das ações. Neste sentido, merece relevo a identificação de alguns responsáveis pela receptação dos produtos subtraídos dos Correios, além de outras fraudes que envolvem valores significativos em dinheiro. Tratam-se de fortes indícios da ligação da criminalidade de massa com o crime organizado, já que os roubos e furtos aos carteiros não seriam movidos apenas pelo senso de oportunidade de alguns criminosos de determinada localidade, ou sem qualquer conexão com uma estrutura organizada.

Durante a operação na região de Itaquera, por exemplo, chegou ao conhecimento dos policiais, inclusive, um caderno escolar onde constam anotações com o roteiro para a ação delituosa contra os carteiros, o que demonstra que os roubos estão sendo até mesmo "ensinados" pelas facções criminosas aos recém ingressos no crime. 
Novas perspectivas na investigação da criminalidade de massa e sua importância...

\section{Conclusão}

A compreensão do que está subjacente à criminalidade organizada deve pautar as indagações dos juristas para além da abordagem meramente normativo-dogmática, posto que, ao focalizar apenas nesse aspecto do fenômeno, é possível que se recaia em uma visão, como diria Tércio Ferraz Jr (2012), demasiadamente restritiva, legalista, cega para a realidade, formalmente infensa à própria existência do fenômeno jurídico como um fenômeno social.

Ao que parece, estaríamos em um ponto de mutação da compreensão dos fenômenos que nos importam, confrontando todos com um novo paradigma, o qual teria como base a teoria dos sistemas e uma teoria da complexidade. (PEREIRA, 2015). Nesta perspectiva, há de se considerar os fenômenos de forma interligada e interdependente. Como vimos, é o que transparece ao analisarmos fenômenos criminais aparentemente distintos como a criminalidade organizada e a criminalidade de massa, porém com grave proximidade e interligação, quando analisados de forma sistêmica.

Ademais, como exposto por Canotilho (2009), estaríamos diante de "um giro antropológico' ou "ruptura antropológica” dos princípios fundantes do direito constitucional e penal, caracterizado pelo garantismo ou hipergarantismo. É um pensamento semelhante ao de Bobbio, que vislumbra uma ruptura com o paradigma atual descrito por ele como "como a era dos direitos", fundado na organização social em torno dos direitos humanos. (BOBBIO apud PEREIRA, 2015).

Portanto, o que estaria movendo a dogmática penal seria

"... a radical mudança de rumo quanto à teleologia intrínseca do próprio sistema penal e das bases antropológicas em que se assenta. Por um lado, ofuncionalismo sistêmico, claramente assumido pelos defensores do "direito penal contra o inimigo", justifica a ideia de res nullius em que se transformam os réus. $O$ "inimigo" nega-se a si próprio como pessoa, aniquila a sua existência como cidadão, exclui-se de forma voluntária e a título permanente da sua comunidade e do sistema juridico que a regula". (CANOTILHO, 2009, p. 23).

O impacto dessa nova perspectiva sistêmica na compreensão da criminalidade de massa também se afigura importante, tendo em vista a perspectiva de embasamento de um novo sistema jurídico que compreenda 
o fenômeno criminoso em sua inteireza, em detrimento do aspecto individualista que rege o sistema de política criminal liberal e que informa nosso modelo constitucional, penal e processual penal.

A aferição das reais conexões entre a criminalidade de massa e o crime organizado somente é viável considerando um novo modelo investigativo para o enfrentamento da criminalidade de massa. É inviável considerar a investigação de todas as ocorrências uniformemente, como estipulado pelo modelo processual defendido por uma grande parte da doutrina, retirando da polícia judiciária o condão de agir com inteligência, dispendendo esforços investigativos apenas quando minimamente viável a solução do delito. Trata-se de uma interpretação equivocada do princípio da obrigatoriedade e dos dispositivos legais, os quais devem ser interpretados em conformidade com outros dispositivos, inclusive com status constitucional, tais como o princípio da eficiência da administração pública e o da proporcionalidade e razoabilidade.

Alguns argumentos esposados no mundo jurídico carregam, em verdade, uma desconfiança quanto a idoneidade e legitimidade da atuação da polícia, em contraste com a realidade verificada na atuação da polícia inglesa. O inquérito policial, no Brasil, deve ser encarado e valorizado como instrumento da investigação criminal, e somente tem sentido se a investigação tiver o mínimo de viabilidade, visto tratar-se de procedimento custoso e excepcional. $\mathrm{O}$ inquérito policial não existe apenas como forma de exercer o controle externo da atividade policial, não obstante ter por característica dar publicidade aos atos da polícia e ser uma garantia do cidadão. O receio de que a polícia judiciária "engavete" investigações, não pode ter o condão de determinar o desvirtuamento do inquérito policial. Os desvios e más condutas podem ser verificados de diversas formas, e estas estão claramente postas quando a polícia está sujeita constitucionalmente ao controle externo.

Além disso, o nosso sistema de política criminal foca no crime, em detrimento do fenômeno criminoso. Ademais, conforme vimos, é tal sistema inadequado ao enfrentamento da criminalidade de massa, haja vista as inúmeras pesquisas e estudos que compõem um modelo aparentemente diametralmente oposto ao estabelecido em nosso país como guia à persecução penal de tais delitos.

A polícia judiciária, que deveria exercer o protagonismo no uso da inteligência para o enfrentamento da criminalidade de massa, em defesa da eficiência das investigações e de uma resposta coordenada que produza 
Novas perspectivas na investigação da criminalidade de massa e sua importância...

conhecimento sobre o fenômeno que está sendo investigado, em verdade é engessada em sua atuação, em nome de um controle social para proteção do cidadão que passa a ser um fim em si mesmo.

Os resultados e recomendações oriundos do Portfólio Hermes da Divisão de Repressão a Crimes Contra o Patrimônio e ao Tráfico de Armas da Polícia Federal demonstra que o enfrentamento da criminalidade de massa pode e deve provocar rupturas na organização do fenômeno criminoso, desde que as investigações sejam orientadas pela inteligência policial, com zelo pela coleta, tratamento e investigação das ocorrências, sem descuidar da atenção às vítimas (a empresa vitimada e o funcionário que sofreu a violência).

Entretanto, como toda ruptura de paradigmas, há de se concretizar na reafirmação das novas posições, com fundamentos que deem uma abordagem zetética ${ }^{8}$ ao problema, indagando sobre pontos até então inquestionáveis. Tal perspectiva esbarra, como já dissemos, pela tradição doutrinária da ciência jurídica, cada vez mais tecnicista, dogmática, fechada e formalista.

\section{Breno Freire Diniz}

O autor é Delegado de Polícia Federal. Bacharel em Direito pela UFPE e especialista em Gestão Integrada pela UNEB. É professor da Academia Nacional de Polícia - ANP/MJ. Ocupou diversas funçóes no Departamento de Polícia Federal, TENDO DESENVOLVIDO O PRESENTE TRABALHO A PARTIR DA EXPERIÊNCIA ObTIDA DURANTE OS QUATRo ANOS LOTAdo Na DiVisão de Repressão a Crimes Contra o Patrimônio e ao Tráfico de Armas da Diretoria de Combate ao Crime Organizado, em Brasília/DF.

E-MAIL: DINIZ.BFD@DPF.GOV.BR

8 A abordagem zetética é mencionada por Tércio Ferraz Jr (2012) em contraposição à dogmática. Zetética vem de zetein, e significa perquirir, já dogmática vem de dokein, e significa ensinar, doutrinar. O enfoque zetético seria mais questionador, com função mais especulativa da investigação científica. 


\title{
New Perspectives on the Investigation of Mass Criminalization and its Importance to Facing Organized Crime
}

\begin{abstract}
The object of this article is the analysis of crimes investigation constituting mass criminality from results obtained on the execution of Hermes2 Portfolio of DPAT - Department of Repression of Crimes Against the Patrimony and Arms trafficking of Federal Police, whose objective was to increase the efficiency on dealing with the crimes of theft and robbery against the mailmen working on the Post and Telegraph Company, in the metropolitan region of Sao Paulo. The results found on that experience show an inedaquacy of the model of criminal persecution established on Brazil to investigate mass criminality, for unconsidering solutions cientifically supported pointing to the inteligence and criminal analysis as essential tools to respond to criminal police. Furthermore, the resurgence of fight against the phenomenon of mass criminality becomes more relevant in the face of evidencies corroborating theoretical construction of the close relation between mass criminality and organized criminality. Thus, it seems necessary the construction of a new paradigm to criminal investigation that reconfigures the model of persecution of mass criminality, adequating it to the changes on legal, dogmatic and ideological values that are remodeling the traditional system of criminal politics, that is to say, liberal and illuminist, influenced mainly by the harmfull reflections of organized criminality in the contemporary society.
\end{abstract}

Key-words: Criminal Investigation. Mass Criminality. Organized Criminality

\section{Nuevas Perspectivas en la Investigación de la Criminalidad de Masa y su Importancia para el Enfrentamiento del Crimen Organizado}

\author{
RESUMEN
}

El objeto de este artículo es el análisis de los crímenes de delincuencia que se refiere a la criminalidad de los resultados obtenidos en la ejecución de Hermes2 Portfolio de DPAT - Departamento de Represión de los delitos contra el patrimonio y el brazo de la policía federal, cuyo objetivo fue aumentar las eficiencias en el control Con los crímenes de theft and robbery contra el correo en el Post and Telegraph Company, en la región metropolitana de Sao Paulo. Los resultados obtenidos en que la experiencia muestra una ininformación del modelo de criminal persecución establecida en el Brasil para investigar la criminalidad, para unconsiderar soluciones científicamente 
Novas perspectivas na investigação da criminalidade de massa e sua importância...

compatibles con la inteligencia y la criminal análisis de las herramientas esenciales para responder a la policía criminal. , La resurgencia de la lucha contra el fenómeno de la delincuencia delictiva se convierte en más relevante en la cara de evidencias corroborando la construcción de la relación de la relación entre la criminalidad y la criminalidad. En el caso de que se produzca un cambio en las condiciones de vida de las personas, las personas con discapacidad, , Liberal y luminoso, influenciado por las repercusiones de la criminalidad en la sociedad contemporánea.

Palabras clave: Investigación Criminal. Criminalidad de Masa. Criminalidad Organizada.

\section{REFERÊNCIAS}

ACPO (Association of Chief Police Officers). Investigation of Volume Crime Manual. London: ACPO, 2002.

BEATO, C.; ZILLI, L. F. Organização Social do Crime. In LIMA, R. S. de (org.), RATTON, José Luiz (org.) AZEVEDO, R. G. Crime, Polícia e Justiça no Brasil. São Paulo: Contexto, 2012.

BECCARIA, Cesare Bonesana, Marchesi di, 1738-1794. Dos delitos e das penas. Tradução: Deocleciano Torrieri Guimarães. São Paulo/SP: Rideel, 2003. - (Biblioteca Clássica).

CANOTILHO, José Joaquim Gomes. Terrorismo e Direitos Fundamentais. In VALENTE, Manoel Monteiro Guedes (Coord.). Criminalidade Organizada e Criminalidade de Massa: Interferências e Ingerências Mútuas. Coimbra: Almedina, 2009.

DELMAS-MARTY, Mireille. Grandes Sistemas de política criminal. Barueri (SP): Manole, 2004.

FERRAZ JÚNIOR, Tércio Sampaio. Introdução ao estudo do direito: técnica, decisão, dominação. São Paulo: Atlas. 6a Edição, 2012.

GUINOTE, HUGO B. Respostas Táctico-policiais ao fenómeno da droga. In VALENTE, Manoel Monteiro Guedes (Coord.). Criminalidade Organizada e Criminalidade de Massa: Interferências e Ingerências Mútuas. Coimbra: Almedina, 2009.

HASSEMER, Winfried. Três temas de Direito Penal. Ed. Escola Superior do Ministério Público. Porto Alegre, 1993.

JANSSON, Krista. Volume crime investigation: a review of the research literature. 2005. Online Report 44/05. Disponível em: webarchive. 
nationalarcheves.gov.uk/20130128103514/http://rds.homeoffice. gov.uk/rds/pdfs05/rdsolr4405.pdf

MULAS, Nieves Sanz. El tráfico de seres humanos ante la ley española. In VALENTE, Manoel Monteiro Guedes (Coord.). Criminalidade Organizada e Criminalidade de Massa: Interferências e Ingerências Mútuas. Coimbra: Almedina, 2009.

PACELLI, Eugênio; FISCHER, Douglas. Comentários ao Código de Processo Penal e sua jurisprudência. São Paulo: Atlas, $4^{a}$ ed., 2012.

SILVA JUNIOR, Tarcísio José da. Operações de Inteligência Aplicadas à Repressão de Crimes Violentos contra o Patrimônio da União: possibilidades e perspectivas no apoio às investigações do DPF. Brasília: Academia Nacional de Polícia, 2014.

SILVA PEREIRA, E. Direito Penal das Organizações Criminosas: Introdução aos Problemas Fundamentais. In SILVA PEREIRA, E. (org.); BARBOSA, EMERSON S. (org.). Organizações Criminosas: Teoria e Hermenêutica da Lei 12.850/2013. Porto Alegre: Núria Fabris, 2015.

SUTHERLAND, Edwin Hardin. A criminalidade de colarinho branco. In Revista Eletrônica de Direto Penal \& Política Criminal - UFRGS. 2014. Disponível em: ser.ufrgs/index/php/redppc/ artcicle/view/56251 Acesso em: 18/11/2016. 